\title{
Doses de radiação gama na conservação da qualidade de morangos
}

\author{
Rita de Cássia Mirela Resende Nassur*, Rafaella Araújo Zambaldi Lima, \\ Luiz Carlos Oliveira Lima, Nilton Nagib Jorge Chalfun
}

Universidade Federal de Lavras, Lavras, MG, Brasil

*Autor correspondente, e-mail: ritarnassur@hotmail.com

\begin{abstract}
Resumo
O morango atrai consumidores por sua coloração vermelha brilhante, odor característico, textura macia e sabor levemente acidificado, possuindo diversos fitoquímicos benéficos à saúde. Caracterizam-se, porém, por alta suceptibilidade às podridões, curta vida útil e não resistência à sanitização. A refrigeração na pós-colheita reduz o metabolismo dos frutos e a aplicação da irradiação pode ser um complemento para maior conservação. O objetivo do trabalho foi avaliar a aplicação de diferentes doses de irradiação gama (0,0 KGy; 0,5 KGy; 1,0 KGy e 1,5 KGy) visando o prolongamento da vida útil e manutenção da qualidade de morangos armazenados em sistema refrigerado $\left(0 \pm 1^{\circ} \mathrm{C}\right.$ e $90 \pm 5 \%$ UR) por 15 dias. Conclui-se que as doses de irradiação gama utilizadas não foram capazes de influenciar substancialmente índices de qualidade e teores de compostos nutricionais de interesse em morangos durante o armazenamento e os frutos mantiveram sua qualidade microbiológica até o fim do período avaliado, independentemente do tratamento utilizado. Frutos irradiados com 1,5 KGy caracterizaram-se pelos maiores teores de antocianinas e apresentaram menor índice visual de podridão em relação aos demais tratamentos no últimos tempos de armazenamento.
\end{abstract}

Palavras-chave: armazenamento refrigerado, Fragaria sp., irradiação gama, qualidade pós-colheita, podridão

\section{Gamma radiation doses on strawberry quality maintenance}

\begin{abstract}
Strawberries attracts consumers due to its bright red color, characteristic odor, soft texture and slightly acid taste, with several phytochemicals groups that can bring health benefits. However, strawberries are very susceptive to decay, with a short shelf life and do not support sanitization. The cooling reduces the metabolism of fruits during postharvest period and the irradiation can be used as a complement to improve fruit preservation. The aim of this study was to evaluate the application different doses of gama irradiation (0,0 KGy; 0,5 KGy; 1,0 KGy e 1,5 KGy) aiming an extended shelf life and quality maintenance of strawberries stored at cold room $\left(0 \pm 1^{\circ} \mathrm{C}\right.$ and $\left.90 \pm 5 \% \mathrm{RH}\right)$ during 15 days. Doses of gama irradiation were not sufficient to change quality parameters and nutritional compounds in strawberries during storage, and the microbiological levels were acceptable until the end of storage period regardless the treatment. Fruit treated with 1,5 KGy were characterized for the higher anthocyanins levels and maintained the lower visual decay index during the last days of storage when compared to other treatments.
\end{abstract}

Key words: cold storage, Fragaria sp., gama irradiation, postharvest quality, decay 


\section{Introdução}

O morangueiro é uma planta herbácea e perene, pertencente à família das Rosáceas, gênero Fragaria. O morango é um fruto muito apreciado devido a sua aparência atraente e sabor característico, seu consumo produz benefícios à saúde humana com efeitos antioxidante, anti-inflamatório e anticarcinogênico, atuando na melhoria da qualidade de vida dos indivíduos (DA SILVAPINTO et al., 2008). As substâncias relacionadas a essas propriedades são o ácido ascórbico e os compostos fenólicos. Vários estudos in vitro, utilizando diferentes metodologias, reportam que o extrato de morango está dentre aqueles com maior atividade antioxidante (VIZZOTTO, 2012).

Tendo em vista os benefícios à saúde, frutos vermelhos vêm despertando a atenção dos produtores e do mercado consumidor mundial, sendo o morango um dos mais importantes representantes deste grupo (FAO, 2005).

Apesar de todas as vantagens do consumo, problemas associados à contaminação microbiológica e redução da vida útil são correntes em morangos e devem ser investigados. O morango é altamente perecível, devido à elevada suscetibilidade ao ataque de fungos (como Botrytis cinerea Pers. e Rhizopus stolonifer (Ehrenb.) Vuill.) que limitam a comercialização (Prasanna et al., 2007). Morangos são também susceptíveis à perda de água e injúrias mecânicas devido à sua textura frágil e falta de uma camada que o proteja (Hernández-Muñoz et al., 2006), fato que dificulta ainda sua sanitização comercial tradicional. Yarahmadi et al. (2014) explicam que morangos possuem uma camada externa muito fina que é muito sensível, e que cerca de $30-40 \%$ dos frutos são perdidos entre a colheita e o consumo devido à sua fragilidade.

A baixa temperatura reduz o metabolismo de frutos durante a pós-colheita e é um importante fator na manutenção da qualidade dos mesmos. A irradiação gama emergiu como um método alternativo aos conservantes químicos, visando a manutenção da qualidade dos produtos, tendo recebido atenção crescente nas últimas décadas em todo em alimentos como fonte de radiação gama e é obtido pelo bombardeamento com nêutrons do metal Cobalto-59 em um reator nuclear. É um processo físico no qual a alta energia ionizante passa através de um produto alvo, aumentando sua segurança pela inativação de micro-organismos, sem deixar resíduos químicos (Khattak e Simpson, 2010).

A aplicação da radiação gama têm gerado resultados satisfatórios em diferentes aspectos da tecnologia de alimentos, como esterilizações, inibição de esporos e aumento da vida útil de frutas e hortaliças (Egea et al., 2007). Com tantos benefícios é importante salientar alguns cuidados com a dosagem. Um estudo realizado por D'Amour et al. (1993) indica que o amolecimento do tecido celular é um fator que limita a utilização da irradiação como método de tratamento pós-colheita. Observouse que morangos irradiados com 4 kGy sofreram amolecimento do tecido e parcial degradação dos polissacarídeos da parede celular, o que sinaliza que a irradiação leva a alterações químicas diferentes das quais o fruto passaria em seu processo normal de amadurecimento. Estas alterações podem ser caracterizadas pela produção de metabólitos secundários e acúmulo de fenólicos e flavonoides em frutos. Com o aumento de doses de irradiação, os teores de compostos fenólicos podem aumentar em resposta à alterações de compostos celulares ou pela decomposição de compostos fenólicos, antes insolúveis (Kavitha et al., 2015).

Levando-se em conta a fragilidade de frutos vermelhos, inclusive o morango, quando submetidos à sanificação, prática indispensável para a segurança alimentar e melhor conservação, a irradiação torna-se uma opção interessante para o prolongamento da qualidade e da vida útil de morangos juntamente com o armazenamento refrigerado. Nesse contexto, o objetivo do trabalho foi avaliar a aplicação de diferentes doses de irradiação gama (0,0 KGy; 0,5 KGy; 1,0 KGy e 1,5 KGy) visando o prolongamento da vida útil e manutenção da qualidade de morangos armazenados em sistema refrigerado $10 \pm 1^{\circ} \mathrm{C}$ e $90 \pm 5 \%$ UR) por 15 dias.

o mundo. O isótopo do Cobalto-60 é utilizado

Com. Sci., Bom Jesus, v.7, n.1, p.38-48, Jan./Mar. 2016 


\section{Material e Métodos}

Frutos comerciais do morangueiro da cultivar Albion, próprios para consumo in natura, foram obtidos no estádio ideal de maturação, em ponto comercial, quando pelo menos $75 \%$ da coloração de cada fruto era vermelho brilhante, na região de Senador Amaral - MG, e recebidos no Laboratório de Fisiologia Pós-colheita de Frutas e Hortaliças do Departamento de Ciência dos Alimentos - UFLA, onde foi retirado o calor de campo pela alocação em câmara fria, por uma noite. Os frutos de todos os tratamentos foram adicionados em caixas de isopor devidamente higienizadas contendo gelox® e transportados em carro refrigerado para o Centro de Desenvolvimento de Tecnologia Nuclear/ Comissão Nacional de Energia Nuclear (CDTN/ CNEN), em Belo Horizonte - MG, para aplicação da irradiação gama nas doses (0,5 KGy; 1,0 KGy e 1,5 KGy), por meio da fonte de Cobalto-60 tipo Gammabeam-650. Em seguida, os frutos foram transportados de volta para o Laboratório de Pós-Colheita da UFLA em ambiente refrigerado e armazenados a $4 \pm 1^{\circ} \mathrm{C}$ e $90 \pm 5 \%$ UR por 15 dias.

Para a realização do experimento, utilizou-se um delineamento inteiramente casualizado em esquema fatorial $4 \times 6$, sendo quatro doses de irradiação (0,0 KGy; 0,5 KGy; 1,0 KGy e 1,5 KGy) e seis tempos de armazenamento $(0,3,6,9,12$ e 15 dias) com três repetições de bandejas com 250 gramas de frutos. As análises físicas, químicas e bioquímicas foram realizadas no Laboratório de Pós- Colheita de Frutas e Hortaliças do Departamento de Ciência dos Alimentos da UFLA.

A cor foi determinada em três pontos distintos dos frutos, utilizando-se o colorímetro Minolta CR-400, com a determinação no modo CIE L*a*b*. A coordenada $L^{*}$ representa quanto mais clara ou mais escura é a amostra, com valores variando de 0 (totalmente preta) a 100 (totalmente branca), geralmente utilizada para verificar o escurecimento; foram obtidas as coordenadas cilíndricas - ângulo Hue de cor ou tonalidade $\left(\mathrm{H}^{\circ}\right)$ que identifica a cor num ângulo de 360 graus, e chroma (C*) que representa a pureza da cor.

As análises físico-químicas descritas a seguir seguiram metodologia da AOAC (2007).
$\mathrm{O} \mathrm{pH}$ foi determinado utilizando-se um pHmetro Schott Handylab e a determinação da acidez titulável foi realizada por titulação com solução de hidróxido de sódio ( $\mathrm{NaOH}$ ) 0,1N, usando como indicador a fenolftaleína. Os resultados foram expressos em porcentagem de ácido cítrico. Os sólidos solúveis totais (\%) foram determinados por refratometria (ATAGO PR-100). A perda de massa fresca foi determinada pesando-se os mesmos frutos em cada tempo de avaliação, em balança semi-analítica. Os resultados foram expressos em percentagem, considerando-se a diferença entre a massa inicial do fruto fresco e aquela obtida a cada intervalo de tempo de amostragem.

Foi realizada a medição da força (N) necessária para que uma sonda de $3 \mathrm{~mm}$, acoplada a um penetrômetro de mão modelo Instrutherm PTR-300, vencesse a resistência da polpa do fruto. A determinação dos fenólicos totais foi realizada utilizando o reagente FolinCiocalteau e os teores foram expressos em mg de equivalentes de ácido gálico (EAG) por 100 gramas do fruto (Waterhouse, 2002). Para a determinação da atividade antioxidante dos frutos, utilizou-se a metodologia baseada na captura do radical DPPH (2,2-Diphenyl-1picrylhidrazil), que produz um decréscimo da absorbância a 515nm (RUFINO et al., 2007), sendo os resultados expressos em porcentagem de sequestro de radicais livres.

A análise do conteúdo total de antocianinas (AT) foi realizada seguindo-se o método do pH diferencial (Giusti e Wrolstad, 2001) e a absorbância final foi calculada por meio da seguinte equação: $A=($ A510nm - A700nm) $\mathrm{pH} 1,0$ - (A510nm - A700nm) pH4,5. O conteúdo de antocianinas totais (AT) foi calculado como cianidina-3-glicosídeo.

Foram também realizadas análises microbiológicas nos frutos (Coliformes e Salmonellas) aos 0, 7 e 15 dias de armazenamento, quando amostras de $25 \mathrm{~g}$ das polpas irradiadas dos frutos foram retiradas aleatoriamente de forma asséptica das embalagens e, em seguida, foi feita a homogeneização em $225 \mathrm{~mL}$ de água peptonada $0,1 \%(\mathrm{p} / \mathrm{v})$ esterilizada, utilizando-se sacos filtro de Stomacher (Seward Limited) e um Stomacher (IUL Instrument), durante 60 segundos. 
Todas as análises foram realizadas segundo a International Commission on Microbiological Specifications for Foods - ICMSF (2000).

Os dados obtidos foram transformados para as unidades internacionais em uso, avaliados quanto à normalidade analisados estatisticamente pelo programa SISVAR (Ferreira, 2008), obtendo-se as médias que foram submetidas à análise de regressão e comparadas em cada tempo de avaliação com auxílio da barra de erros. Para a análise multivariada, dados de todas as variáveis foram autoescalonados utilizando-se $\bigcirc$ programa Unscramble ${ }^{\circledR} \quad$ e submetidos à análise de componentes principais (ACP) através do Software XLStat.

\section{Resultados e Discussão}

$\mathrm{Na}$ figura 1 pode-se analisar o comportamento dos valores de coloração observados nos frutos durante o armazenamento (L*, Chroma e Hue). Observa-se que não houve mudanças nos valores dos parâmetros analisados quando comparados o início e no final do armazenamento. O parâmetro L* de coloração pode ser um indicador da senescência e degradação de pigmentos, mais acentuada em frutos não tratados, porém sem diferença estatisticamente significativa.

Para a cromaticidade, no decorrer do experimento os valores entre os tratamentos foram invertidos em relação aos iniciais. Ao fim dos 15 dias de armazenamento, observase que os frutos com maior grau de pureza da cor eram do tratamento controle, seguido das dosagens de 0,5 KGy, 1,5 KGy e 1,0 KGy (Figura 1B). Estatisticamente nenhuma das dosagens influenciou significativamente nos valores desse parâmetro, de acordo com o teste de médias realizado. Na figura $1 C$, pode-se observar os resultados para o ângulo Hue, que identifica a cor num ângulo de $360^{\circ}$, onde apenas no sexto dia de armazenamento refrigerado houve uma diferença significativa na coloração, de acordo com as doses utilizadas (Figura 1C). A partir do dia 3 até o dia 12, observamos que os frutos com maiores valores para Hue foram os de dosagem 1,5 KGy, 0,5 KGy o controle, e a dosagem 1,0 $K G y$, respectivamente. O ângulo Hue indica frutos mais vermelhos aqueles que estão mais próximo ao ângulo 0 , seguindo para amarelos ou esverdeados quando observa-se um Ângulo hue próximo a $90^{\circ}$. Independente da dose de radiação utilizada, a coloração dos frutos não diferenciou-se significativamente, mantendo os frutos atrativos para o consumidor.

\section{$L^{*}$}
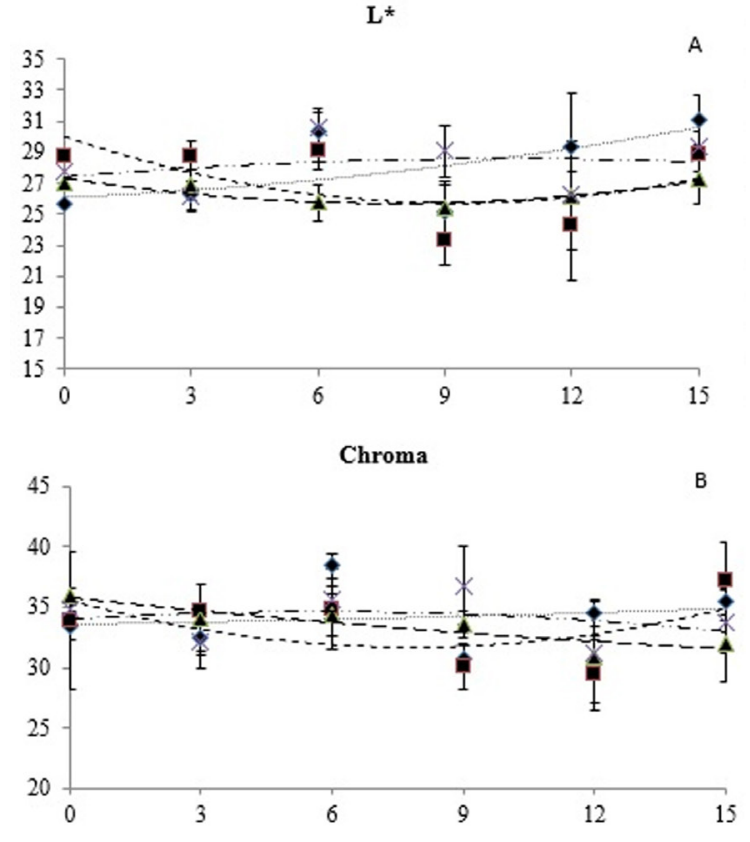

Hue

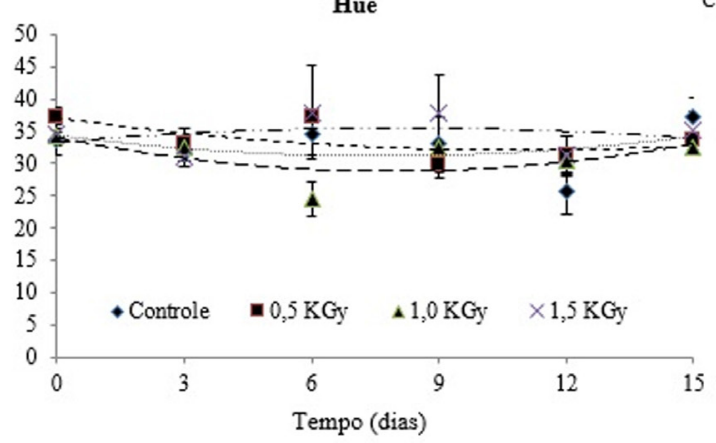

Figura 1. Valores de $L^{*}(A)$, cromaticidade (B) e ângulo Hue (C) de morangos submetidos a doses de irradiação gama $(0$; $0,5 ; 1,0 ; 1,5 \mathrm{KGy})$ e armazenados por até 15 dias a $4 \pm 1{ }^{\circ} \mathrm{C}$ e $90 \pm 5 \%$ UR.

$\mathrm{O} \mathrm{pH}$ dos frutos avaliados foi em média 3,5 (Figura 2A) e não houve diferença significativa entre as dosagens de irradiação para que afetassem $\mathrm{opH}$ dos frutos ao longo do armazenamento refrigerado. Françoso et al (2008), trabalhando com morangos irradiados e armazenados, observaram valores condizentes de $\mathrm{pH}$ com os aqui encontrados, variando de 3,3 a 3,62 , valores esses também condizentes com valores de 3,53 a 3,69 descritos por Domingues 
(2000).

Para a acidez total titulável (Figura 2B), nenhuma das doses de irradiação apresentou diferença estatisticamente significativa durante os 15 dias do experimento. No final do armazenamento, somente a maior dose de irradiação contribui para um aumento da acidez dos frutos. Os ácidos orgânicos presentes nos frutos, em balanço com os teores de açúcares, representam um importante atributo de qualidade. Muitos desses ácidos são voláteis, contribuindo, dessa forma, para o aroma característico dos frutos.
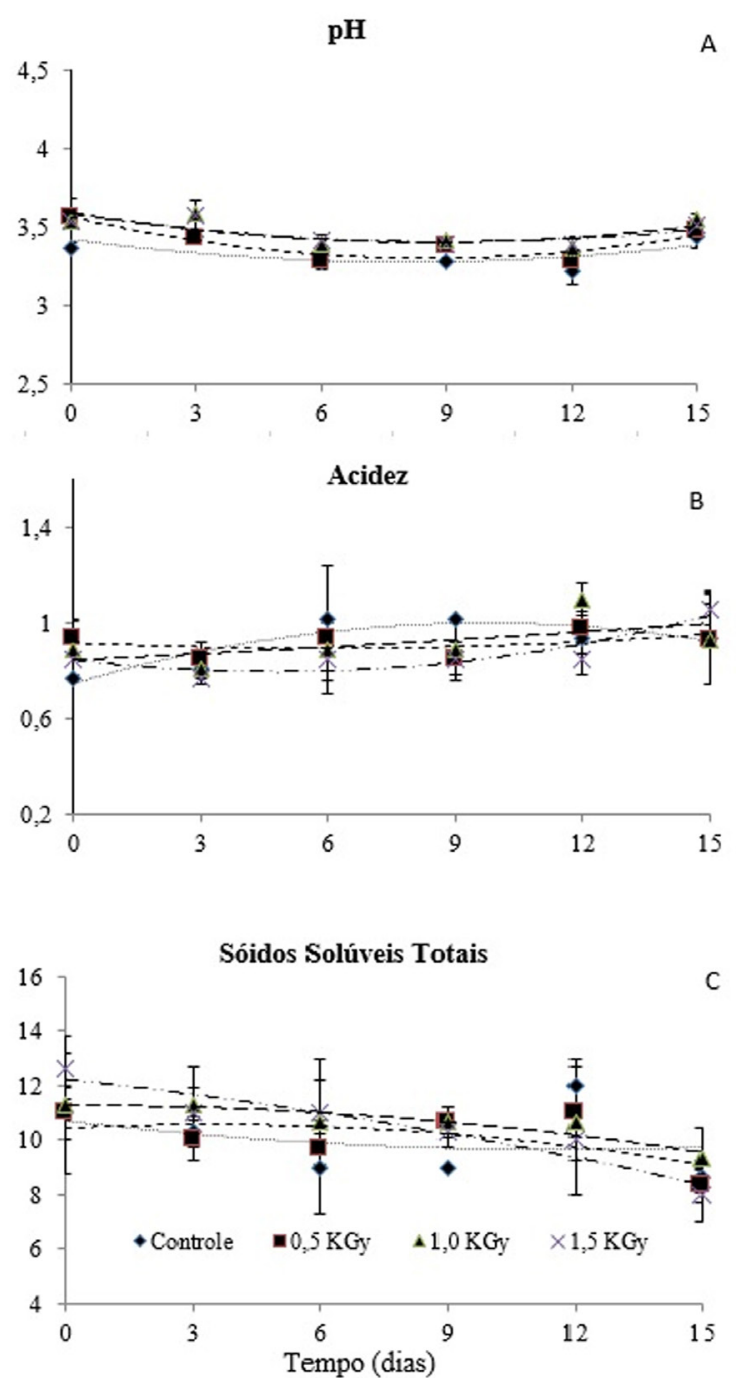

Figura 2. Valores de ph (A), acidez total titulável (B) e sólidos solúveis totais de morangos submetidos a doses de irradiação gama $(0 ; 0,5 ; 1,0 ; 1,5 \mathrm{KGy})$ e armazenados por até 15 dias a $4 \pm 1{ }^{\circ} \mathrm{C}$ e $90 \pm 5 \%$ UR.

Na Figura 2A pode-se observar uma tendência à estabilização dos teores de acidez para frutos do morangueiro controle e submetidos a diferentes doses de irradiação, sendo mantidos por até 15 dias em armazenamento refrigerado. Os valores de acidez titulável observados $(0,78$ a $1,1 \mathrm{mg}$ ácido cítrico $100 \mathrm{~g}^{-1}$ de polpa) estão de acordo com os valores observados por Domingues (2000) (entre 0,85 e $0,99 \mathrm{mg} 100$ $\left.\mathrm{g}^{-1}\right)$. Mokhtar e colaboradores (2014) afirmam que os ácidos orgânicos, responsáveis pela acidez diminuem durante $\mathrm{o}$ amadurecimento e armazenamento e que possuem grande importância nas plantas, pois são intermediários dos processos metabólicos, incluindo respiração e fotossíntese, contribuindo para a maturação e senescência dos frutos.

O teor de sólidos solúveis totais (SST) nos frutos com ou sem dosagem de irradiação, não sofreu alteração significativa ao longo dos 15 dias de armazenamento (Figura 2C). Observa-se que os frutos com dosagem 1,5 KGy tiveram a maior concentração de sólidos solúveis, seguidos dos demais que não se diferenciaram, e que no dia 12, o controle obteve a maior concentração de SST. Aos 15 dias de armazenamento os frutos não diferenciaram entre si quanto aos teores de sólidos solúveis totais. Chandra et al. (2015) relatam que o teor de sólidos solúveis em morangos pode diminuir durante o armazenamento, conclusão realizada quando avaliaram morangos controle e em atmosfera controlada. Os morangos aqui avaliados sofreram uma leve queda nos tores de SST durante o armazenamento refrigerado, porém essa alteração não foi significativa.

$\mathrm{Na}$ Figura 3A, observa-se a relação entre teores de sólidos solúveis totais e acidez titulável (SST/AT) que representa um balanço entre açúcares e ácidos orgânicos solubilizados no fruto, sendo um importante indicativo de qualidade para o consumido. Não observase grandes mudanças na relação SST/AT em cada tempo de armazenamento, entre os tratamentos estudados. A tendência da relação entre sólidos solúveis totais (SST) e acidez (AT), foi de queda durante 0 armazenamento, independentemente do tratamento utilizado, e durante o armazenamento, observa-se uma redução de 32,79\% da relação SST/AT, em média.

A perda de massa fresca aumentou ao longo de todo o armazenamento (Figura 3B). Aos 12 e 15 dias de armazenamento, frutos controle 
perderam mais massa em relação aos frutos irradiados. No último tempo, as médias de perda de massa de frutos não irradiados e irradiados foram de $39,7 \%$ e $33,8 \%$, respectivamente, colaborando para que a aparência do fruto fosse um pouco prejudicada nesse tempo de avaliação. A migração de água do fruto para - ambiente é a maior causa de perda de massa em frutos durante o armazenamento (Duan et al., 2011). Do sexto ao nono dia de armazenamento, os morangos irradiados com a dose de 1,0 KGy apresentaram os menores valores de perda de massa fresca, chegando a $17,8 \%$ no nono dia, comparado aos demais tratamentos (24,9\%). Guimarães et al. (2013) estudando o efeito da irradiação gama $\mathrm{CO}^{60}$ em framboesas armazenadas a $1^{\circ} \mathrm{C}$ por 12 dias observaram que as doses de irradiação 0,5, 1,0 e 2,0 kGy minimizaram a perda de massa fresca em comparação com os frutos não tratados. No último dia de armazenamento todos os frutos apresentavam-se murchos e com a aparência prejudicada devida a grande perda de massa fresca. Morangos são altamente susceptíveis à rápida perda de massa fresca, que resulta em murchamento dos frutos e enfraquecimento do tecido (Velickova et al., 2013).

A firmeza dos frutos (Figura $3 \mathrm{C}$ ) mantevese estável ao longo do armazenamento, para todos os tratamentos estudados. Entre os dias $9 \mathrm{e}$ 12, frutos controle mostraram-se mais firmes que os demais. A manutençã $\square$ o da firmeza de frutos durante o armazenamento é considerada um fator de grande importância para a conservação da qualidade dos mesmos, indicando que a degradação de compostos de parede celular ocorre em uma taxa reduzida, com consequente redução do ataque de micro-organismos.

$$
\text { As principais características }
$$
relacionadas à qualidade de morangos durante o amadurecimento são textura, sabor (SST e AT) e a coloração (inclusive os teores de antocianinas). Geralmente, a perda de qualidade ocorre devida à sua alta atividade metabólica e sensibilidade ao ataque de fungos. Mudanças na textura de morangos são consequência de um processo natural de senescência e podem variar de acordo com a atmosfera de armazenamento. Além disso, mudanças óbvias na aparência e contaminação por fungos modificam a textura dos frutos, podendo influenciar a sua vida útil (Chandra et al., 2015).
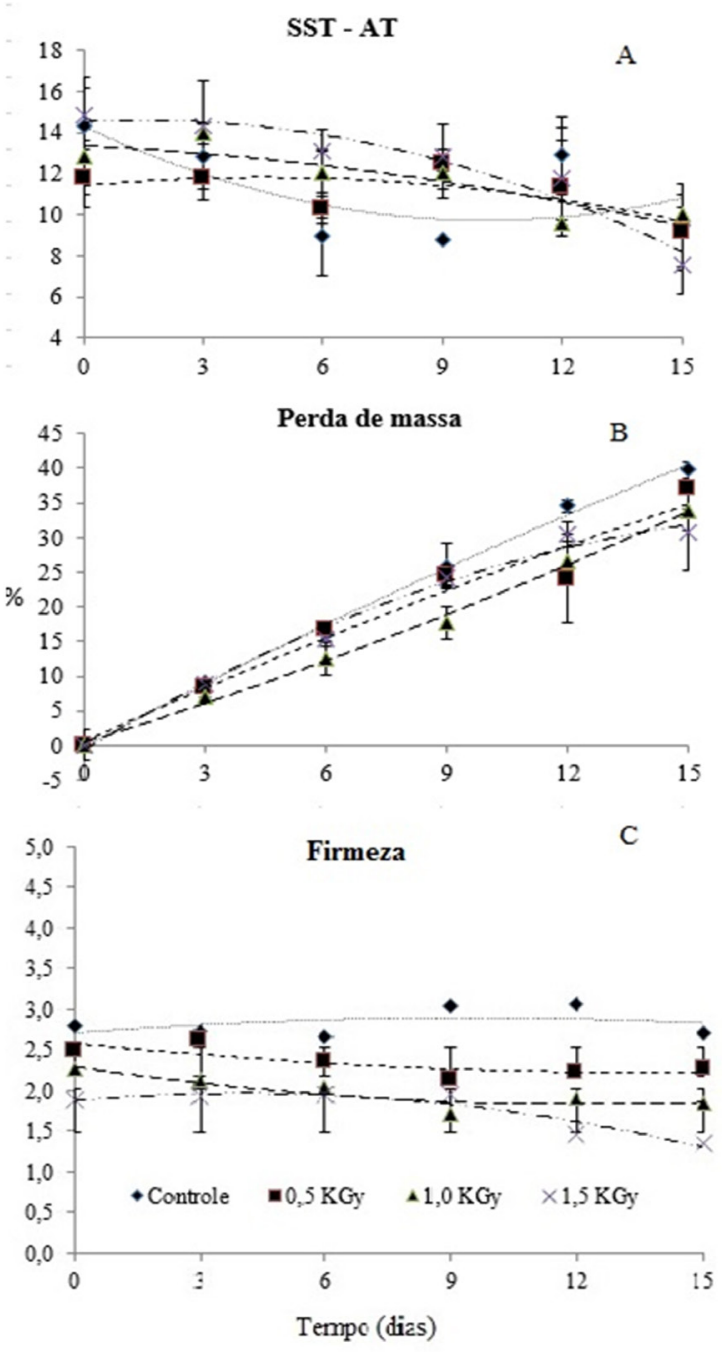

Figura 3. Relação SST/AT (A), perda de massa (B) e firmeza $\mathrm{N}$ - (C) de morangos submetidos a doses de irradiação gama (0; 0,$5 ; 1,0 ; 1,5 \mathrm{KGy}$ ) e armazenados por até 15 dias a $4 \pm 1{ }^{\circ} \mathrm{C}$ e $90 \pm 5 \%$ UR.

Os compostos fenólicos representam a maior classe de agentes fitoquímicos e estão distribuídos amplamente no reino vegetal e são de grande importância na qualidade dos alimentos, já que representam um grande grupo de compostos cominteressante poder nutricional. A identificação de frutos com compostos fenólicos, assim como sua manutenção em frutos tratados e armazenados é de extrema importância quando trata-se de qualidade de frutos. O teor de fenólicos totais, independente do tratamento, mantive uma média em torno de

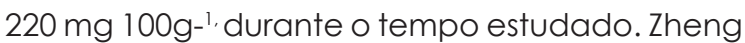
et al (2007), utilizando-se da mesma técnica deste trabalho, observou que morangos (cv 
Allstar) durante $\mathrm{O}$ armazenamento continham de 102 a 117 mg de compostos fenólicos com 100 gramas de fruto.

Tratamentos que possam influenciar em teores de compostos de interesse no morango devem ser avaliados para que seja levada em consideração a viabilidade nutricional do seu uso, pois uma perda nesses teores seria indesejável. Verificou-se no presente trabalho que no tempo 0 , ou seja, imediatamente após a aplicação dos tratamentos, frutos irradiados com as maiores doses (1,0 KGy e 1,5 KGy) resultaram em maior atividade antioxidante, com valores de $80 \%$ e $70 \%$ de sequestro de radicais livres pelo método do DPPH (SRL), respectivamente, comparados com os tratamentos controle e $0,5 \mathrm{KGy}$ que apresentaram valor médio de $61,25 \%$ (SRL) (Figura 4B). Durante o período de armazenamento a porcentagem média de atividade antioxidantes dos morangos irradiados com as doses de 1,0 GKy e 1,5 KGy foram mantidas. Os demais frutos (controle e irradiados com 0,5 KGy) apresentaram aumento nos valores de atividade antioxidante no decorrer do armazenamento, fato que pode ser explicado devido ao efeito concentrador da perda de umidade ao longo do armazenamento, o que faz com que os compostos responsáveis pela atividade antioxidante fiquem concentrados e apresentem valores aparentemente maiores. Alguns estudos têm demonstrado que a aplicação da irradiação na pós-colheita de frutas e hortaliças provoca um estresse que induzem a produção de metabólitos secundários provenientes da ativação do mecanismo de defesa dos vegetais, tais como os compostos fenólicos (Wang et al., 2009; Alothman et al., 2009; González-Aguilar et al., 2007).

As antocianinas são um dos compostos que representam os flavonoides e contribuem grandemente para a qualidade dos frutos, seja visualmente, conferindo coloração atrativa ou por sua grande contribuição na atividade antioxidante (Lopes et al., 2007). Em relação aos teores de antocianinas monoméricas quantificados nos frutos (Figura $4 \mathrm{C}$ ), não foi observada uma tendência geral dos teores durante $o$ armazenamento para os tratamentos utilizados. No primeiro tempo de avaliação, frutos controle e os que receberam a dose de irradiação de 0,5 KGy, apresentaram maiores teores de antocianina $\left(23,9 \mathrm{mg} 100 \mathrm{~g}^{-1}\right.$ e 25,9 mg $100 \mathrm{~g}^{-1}$, respectivamente). Ao final, no tempo 15, o tratamento 1,5 KGy apresentou maior teor de antocianinas $\left(26,3 \mathrm{mg} 100 \mathrm{~g}^{-1}\right), 0$ que influenciou na diferenciação do mesmo quando a análise de componentes principais foi realizada. Hussain, Dar e Wani (2012) analisando morangos revestidos com carboximetil celulose e irradiados com a dose de 2,0 KGy, mantidos sob refrigeração por 21 dias, não observaram diferença entre os valores de antocianina de frutos irradiados e não irradiados. Segundo os mesmos autores, nos frutos irradiados foi observada queda nos valores de antocianina após $015^{\circ}$ dia de armazenamento.
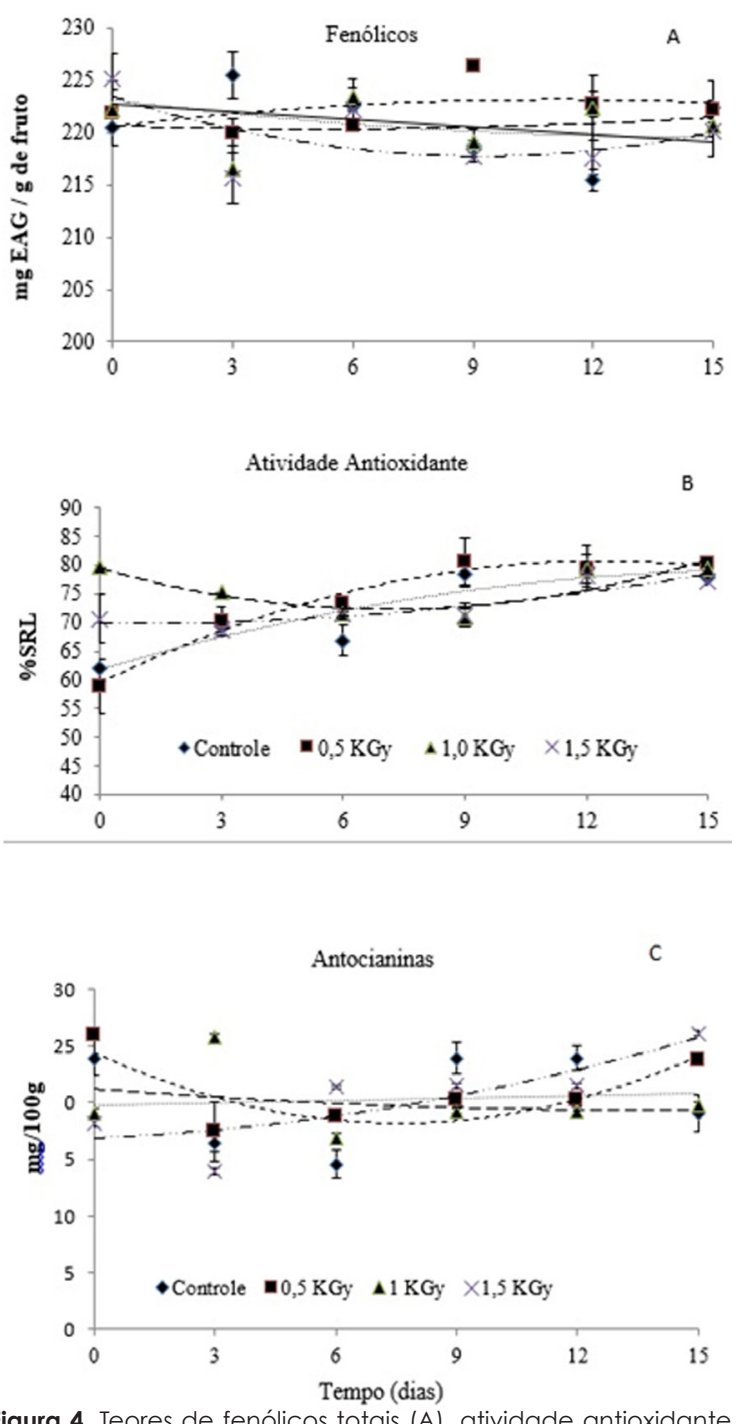

Figura 4. Teores de fenólicos totais (A), atividade antioxidante (B) e antocianinas monoméricas de morangos submetidos a doses de irradiação gama (0; 0,5; 1,0; 1,5 KGy) e armazenados por até 15 dias a $4 \pm 1{ }^{\circ} \mathrm{C}$ e $90 \pm 5 \%$ UR. 
Khattak e Simpson (2010) afirmam que o uso da irradiação gama em doses adequadas não influencia significativamente teores de macronutrientes e micronutrientes dos frutos, como o caso de Vitaminas, que contribuem para o potencial antioxidante dos frutos.

Alighourchi et al. (2008), afirmaram que diferentes doses de irradiação gama aplicadas afetam significativamente os teores de antocianinas em sucos e que quanto menor a dose, maior a retenção desses compostos nos frutos (avaliações de 0,5 a $10 \mathrm{KGy}$ ). Assim, podese inferir que as doses aqui utilizadas não foram suficientes para influenciar na manutenção ou perda desses compostos, ocorrendo a manutenção desses parâmetros de qualidade com a irradiação. Talvez a utilização de doses maiores ou com maiores incrementos de KGY pudessem resultar em algumas modificações nos teores de antocianinas.

Severo et al. (2011) comentaram ainda que o conteúdo de fitoquímicos nos frutos pode ser afetado pelo grau de maturação e condições ambientais durante a colheita, por diferenças genéticas entre cultivares, pela manipulação e tratamento dos frutos e por condições de estocagem na pós-colheita.

Apesardomorangoserfonte de vitaminas e compostos com propriedades funcionais, sua vida útil é limitada, devido especialmente à alta atividade de microorganismos e respiratória. Assim, é de grande importância a observação da microbiologia dos frutos e a verificação das mudanças em seus perfis microbiológicos com o tratamento utilizado. Na tabela 1, pode-se observar que as doses de irradiação gama utilizadas não foram suficientes para que a contagem ou observação da presença de microorganismos fossem alteradas, em avaliações realizadas aos 0,7 e 15 dias de armazenamento dos frutos. Assim, conclui-se que os frutos estavam em qualidade microbiológica satisfatória durante $\mathrm{o}$ armazenamento, independente do tratamento com uso da irradiação gama.

Tabela 1. Valores de Coliformes a $45^{\circ} \mathrm{C}$ e detecção de Salmonellas encontrados em análises microbiológicas para diferentes dosagens de irradiação aplicadas em morangos.

\begin{tabular}{cccc}
\hline Tempo (dias) & Doses & \multicolumn{1}{c}{ E. coli } & Salmonella sp \\
\hline \multirow{2}{*}{0} & Controle & $<0,03 \times 10^{2} \mathrm{NMP} / \mathrm{g}$ fruto & Ausente \\
& $0,5 \mathrm{KGy}$ & $<0,03 \times 10^{2} \mathrm{NMP} / \mathrm{g}$ fruto & Ausente \\
& $1,0 \mathrm{KGy}$ & $<0,03 \times 10^{2} \mathrm{NMP} / \mathrm{g}$ fruto & Ausente \\
& $1,5 \mathrm{KGy}$ & $<0,03 \times 10^{2} \mathrm{NMP} / \mathrm{g}$ fruto & Ausente \\
\hline Controle & $<0,03 \times 10^{2} \mathrm{NMP} / \mathrm{g}$ fruto & Ausente \\
& $0,5 \mathrm{KGy}$ & $<0,03 \times 10^{2} \mathrm{NMP} / \mathrm{g}$ fruto & Ausente \\
7 & $1,0 \mathrm{KGy}$ & $<0,03 \times 10^{2} \mathrm{NMP} / \mathrm{g}$ fruto & Ausente \\
& $1,5 \mathrm{KGy}$ & $<0,03 \times 10^{2} \mathrm{NMP} / \mathrm{g}$ fruto & Ausente \\
\hline Controle & $<0,03 \times 10^{2} \mathrm{NMP} / \mathrm{g}$ fruto & Ausente \\
& $0,5 \mathrm{KGy}$ & $<0,03 \times 10^{2} \mathrm{NMP} / \mathrm{g}$ fruto & Ausente \\
15 & $1,0 \mathrm{KGy}$ & $<0,03 \times 10^{2} \mathrm{NMP} / \mathrm{g}$ fruto & Ausente \\
& $1,5 \mathrm{KGy}$ & $<0,03 \times 10^{2} \mathrm{NMP} / \mathrm{g}$ fruto & Ausente \\
\hline
\end{tabular}

A ausência de Salmonellas foi comprovada em todas as amostras avaliadas e a contagem de coliformes a $45^{\circ} \mathrm{C}$ manteve-se abaixo do limite máximo permitido pela ANVISA (2001), a despeito das dosagens de irradiação utilizadas (Tabela 1). A RDC n¹2, de 12 de janeiro de 2001 da ANVISA, exige para hortaliças, ausência de Salmonella sp e máximo de $10^{2}$ coliformes a $45^{\circ} \mathrm{C}$ em cada grama da hortaliça in natura, inteira, selecionada ou não.

Na figura 5 podemos observar a análise de componentes principais realizada levando em consideração todos os parâmetros de qualidade aqui avaliados, com a média durante todo o período de armazenamento. A análise realizada explica, nos dois eixos, $81,17 \%$ dos resultados. Amostras localizadas mais à direita (CP1) caracterizam-se por apresentarem maior perda de massa e valores referentes à coloração ( $L^{*}$ e Hue). Por outro lado, se projetarmos as variáveis no eixo $X_{-}$, podemos inferir que frutos aqui tratados com doses de 1,0 KGy relacionamse mais com a atividade antioxidante. Maiores teores de antocianinas e compostos fenólicos 
fazem com que as amostras sejam direcionadas para o eixo $\mathrm{Y}+(\mathrm{CP} 2)$, assim como teores diferenciados Chroma e relação SST/AT fazem com que amostras controle, 1,0 e 1,5 KGy sejam colocadas em quadrantes da CP2 (eixo Y-).

Biplot (axes F1 and F2: $81,17 \%$ )

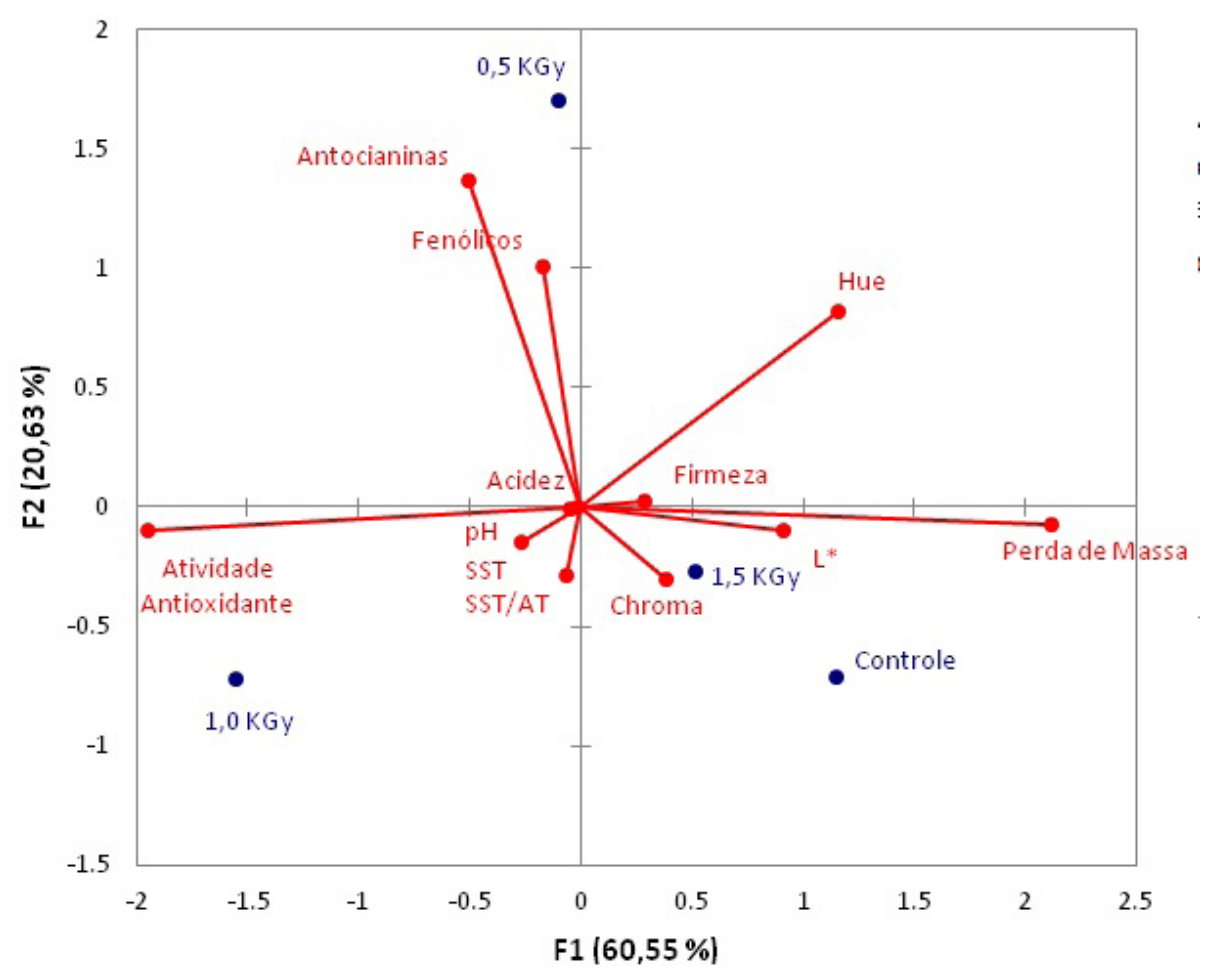

Figura 5. Análise de componentes principais de morangos controle e submetidos a doses de irradiação gama $(0 ; 0,5 ; 1,0 ; 1,5 \mathrm{KGy})$ e armazenados por até 15 dias a $4 \pm 1^{\circ} \mathrm{C}$ e $90 \pm 5 \%$ UR.

O tratamento com a dose de 0,5 KGy destacou-se com os maiores teores de atividade antioxidante em relação aos demais. Frutos que não sofreram irradiação gama foram caracterizados por uma maior perda de massa e também continham maior brilho (valores de L*) em relação àqueles irradiados.

Na Figura 6, pode-se observar amostras de morangos aos 12 dias de armazenamento refrigerado nos quatro tratamentos avaliados. Pode-se perceber que a podridão, que é um grande problema encontrado em morangos, foi controlada com as doses de irradiação e foi visualmente menor com o incremento das doses, com a vantagem de que as características de qualidade dos frutos não terem sido alteradas com as diferentes doses de irradiação em relação quando morangos foram submetidos à irradiação. Cai et al. (2015), trabalhando com controle da podridão em morangos, observaram que os tratamentos utilizados (controles biológicos) diminuíram significativamente a podridão dos frutos, mantendo a firmeza, teores de sólidos solúveis totais e $\mathrm{pH}$, assim como ocorreu com os frutos neste trabalho analisados.

\section{Conclusões}

Irradiação gama nas doses de 1,0 KGy e 1,5 KGy mantiveram menor perda de massa fresca e maior atividade antioxidante logo após a aplicação dos tratamentos, prolongando a vida útil de morangos com qualidade.

Irradiação gama na dose de 1,5 KGy controla visualmente a podridão dos morangos.

Frutos controle e irradiados mantiveramse com contagem de Coliformes abaixo do limite exigido pela legislação, e com ausência de Salmonella sp.

\section{Agradecimentos}

Ao CDTN/UFMG pela estrutura e ao CNPq pelo apoio financeiro. 


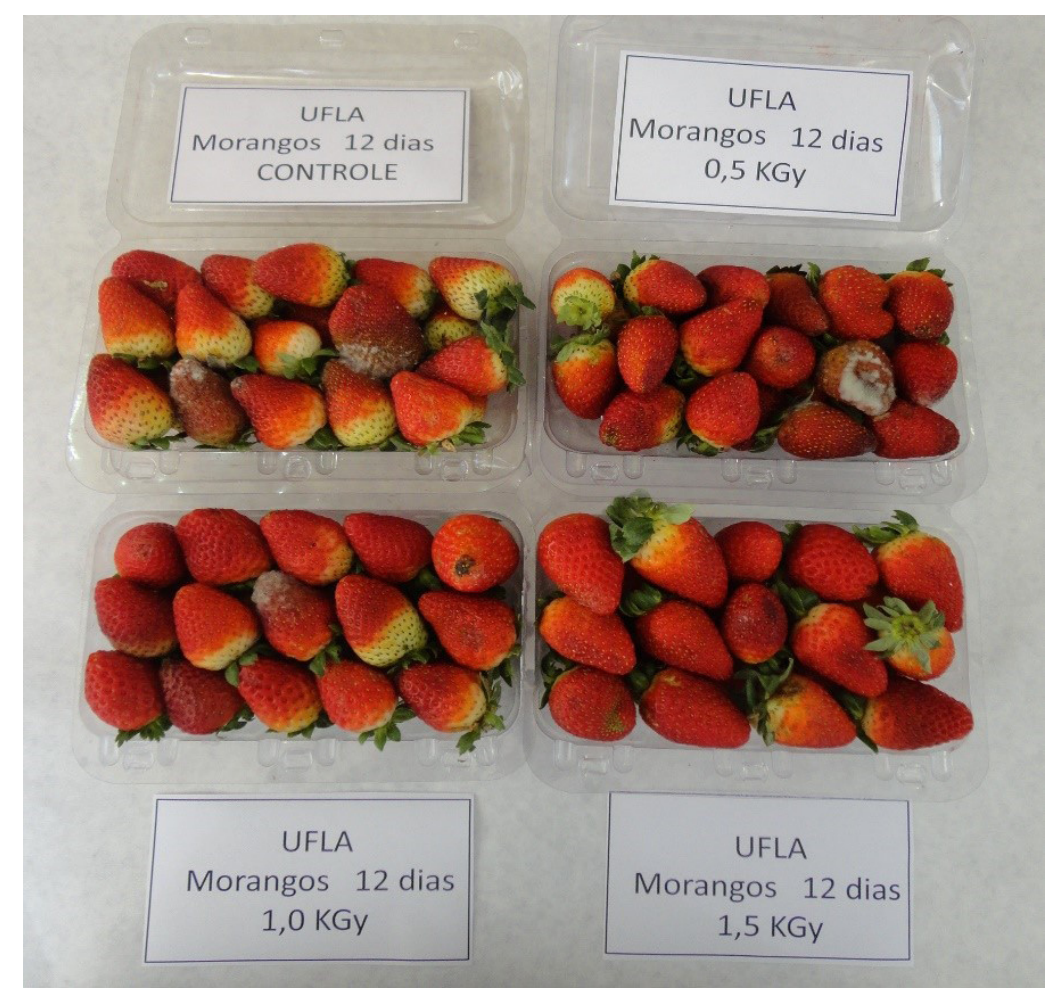

Figura 6. Morangos submetidos a doses de irradiação gama (0; 0,5; 1,0; 1,5 KGy) e armazenados por 12 dias a $4 \pm 1^{\circ} \mathrm{C}$ e $90 \pm 5 \%$ UR.

\section{Referências}

Aligourchi, H., Barzegar, M., Abbasi, S. 2008. Effect of gamma irradiation on the stability of anthocyanins and shelf-life of various pomegranate juices. Food Chemistry. 110 (4): 1036-1040.

Alothman, M., Bhat, R., Karim, A. A. 2009. UV radiation-induced changes of antioxidant capacity of fresh-cut tropical fruits. Innovative Food Science and Emerging Technologies 10: 512-516.

AOAC - Association of Analytical Chemistry. 2007. Official methods of analysis of the Association of Official Analytical Chemistry. 17thed. Washington.

Cai, Z., Yang, R., Xiao, H., Qin, X., Si, L. 2015. Effect of preharvest application of Hanseniaspora uvarum on postharvest diseases in strawberries. Postharvest Biology and Technology 100: 52-58.

Chandra, D., Choi, A.J., Lee, J.S., Lee, L., Kim, J.G. 2015. Changes in Physicochemical and Sensory Qualities of "Goha" Strawberries Treated with Different Conditions of Carbon Dioxide. Agricultural Sciences 6 (3): 325-334.

Da Silva Pinto, M., Lajolo, F.M., Genovese, M.I. 2008. Bioactive compounds and quantification of total ellagic acid in strawberries (Fragaria ananassa Duch.). Food Chemistry 107:1629-1635.

D'amour, J., Gosselin, C., Arul, J., Castaigne, F., Willemot, C. 1993. Gamma-radiation affects cell wall composition of strawberries. Journal of Food Science 58: 182-185.

Domingues, D. M. 2000. Efeito da radiação gama e embalagem na conservação de morangos "Toyonoka" armazenados sob refrigeração. Piracicaba, 58p. Dissertação - (Mestrado), Universidade de São Paulo, Piracicaba, Brasil.

Duan, J., Wu, R., Strik, B. C., Zhao, Y. 2011 . Effect of edible coatings on the quality of fresh blueberries (Duke and Elliott) under commercial storage conditions. Postharvest Biology and Technology 59: 71-79.

Egea, M.I., Sanchez-Bel, M.C., MartinezMadrid, F.B., Flores, F.B., Romojaro, F. 2007. The effect of beta ionization on the antioxidant potential of "Bulida" apricot and its relationship with quality. Postharvest Biology and Technology 46: 63-70.

FAO - FAOSTAT. Statistios Division 2005. Disponível em: <http://faostat.fao.org/site/408/ DesktopDefault.aspx? Page ID=408>. <Acesso em: 10 ago 2014>.

Ferreira, D. F. 2008. SISVAR: um programa para análises e ensino de estatística. Revista Symposium 6: 36-41.

Françoso, I.L.T., Couto, M.A.L., Canniati-Brazaca, S. G., Arthur, V. 2008. Alterações físico-químicas em morangos (Fragaria anassa Duch.) irradiados e armazenados. Ciência e Tecnologia de Alimentos 28(3): 614-619. 
Giusti, M.M., Wrolstad, R. E. 2001. Anthocyanins. Characterization and Measurement with UVVisible Spectroscopy. In: Wrolstad, R. E. (Ed.). Current Protocols in Food Analytical Chemistry. John Wiley \& Sons., New York, USA. Unit. F1.2.1-13

González-Aguilar, G.A., Villegas-Ochoa, M.A., Martínez-Télez, M.A., Gardea, A.A., Ayala-Zavala, J.F. 2007. Improving antioxidant capacity of freshcut mangoes treated with UV-C. Journal of Food Science 72: 197-202.

Guimarães, I.C., Menezes, E.G.T., Abreu, P.S., Rodrigues, A.C., borges, P.R.S., Batista, L.R., Cirilo, M.A., Lima, L.C.O. 2013. Physicochemical and microbiological quality of raspberries (Rubus idaeus) treated with different doses of gamma irradiation. Food Science and Technology 33: 316-322.

Hernandez-Munoz, P., Almenar, E., Ocio, M.J., Gavara, R. 2006. Effect of calcium dips and chitosan coatings on postharvest life of strawberries (Fragaria $\times$ ananassa). Postharvest Biology and Technology 39: 247-253.

Hussain, P.R., Dar, M.A., Wani, A.M. 2012. Effect of edible coating and gamma irradiation on inhibition of mould growth and quality retention of strawberry during refrigerate storage. International Journal of Food Science $e$ Technology 47: 2318-2324.

ICMSF- International Commission on Microbiological Specification for Foods. 2000. Técnicas de las análises microbiológicas. Acribia, Zaragoza, Espanha. 430 p.

Kavitha, C., Aparna Kuna, A., Supraja, T., Blessy Sagar S., Padmavathi, T.V.N., Prabhakar, N. 2015. Effect of gamma irradiation on antioxidant properties of ber (Zizyphus mauritiana) fruit." Journal of food science and technology 52 (5): 3123-3128.

Khattak K.F., Simpson T.J. 2010. Effect of gamma irradiation on the antimicrobial and free radical scavenging activities of Glycyrrhiza glabra root. Radiation Physical Chemistry 79: 507-512

Mokhtar, S.I., Leong, P.C., Vem, L.E., Aziz, N.A.A. 2014. Total Phenolic Contents, Antioxidant Activities and Organic Acids Composition of Three Selected Fruit Extracts at Different Maturity Stages. Journal of Tropical Resouces and Sustaintable Science 2: 40-46.

Prasana, V., Prabha, T.N., Tharanthan, R.N. 2007. Fruit ripening phenomena - An overview. Critical Reviews in Food Science and Nutrition 47(1): 1-19.

Rufino, M.S.M., Alves, R.E., Morais, S.M., Sampaio, C.G., Perez-Jimenez, J., Saura-Calixto, F.D. 2007. Metodologia cientifica: Determinação da atividade antioxidante total em frutas pela captura do radical livre DPPH. Comunicado Técnico Embrapa. ISSN 1679 6535, Fortaleza, CE.

Severo, J., Tiecher, A., Chaves F.C., Silva, J.A., Rombaldi, C.V. 2011. Gene transcript accumulation associated with physiological and chemical changes during developmental stages of strawberry cv. Camarosa. Food Chemistry 126(3): 995-1000.

Velickova, E., Winkelhausen, E., Kuzmanova, S., Alves, V. D. 2013. LWT - Food Science and Technology Impact of chitosan-beeswax edible coatings on the quality of fresh strawberries ( Fragaria ananassa CV Camarosa) under commercial storage conditions. LWT - Food Science and Technology 52: 80-92.

Vizzoto, M. 2012. Propriedades funcionais das pequenas frutas. Informe Agropecuário. Belo Horizonte. v.33 (268): p.84-88.

Wang, C. Y., Chen, C., Wang, S. Y. 2009. Changes of flavonoid content and antioxidant capacity in blueberries after illumination with UV-C. Food Chemistry 117: 426-431.

Waterhouse, A.L. 2002. Polyphenolics: Determination of total phenolics in Current Protocols in Food Analytical Chemistry, John Wiley \& Sons, New York, USA. 1118 p.

Yarahmadi, M., Azizi, M., Morid, B., Kalatejari, S. 2014. Postharvest application of gum and mucilage as edible coating on postharvest life and quality of strawberry fruit. International Journal of Advanced Biological and Biomedical Research 2(4):1279-1286.

Zheng, Y., Wang, S.Y., Wang, C.Y., Zheng, W. 2007. Changes in strawberry phenolics, anthocyanins, and antioxidant capacity in response to high oxygen treatments. LWT 40:49-57. 